\title{
Progressive hypokalaemia in elderly patients taking three thiazide potassium-sparing diuretic combinations for thirty-six months
}

\author{
Nick Sawyer* and Roger Gabriel
}

St Mary's Hospital, Praed Street, London W2 INY, UK.

\begin{abstract}
Summary: Three different thiazide potassium-sparing diuretic combinations were given to elderly patients for heart failure. Eighty patients received their allocated combinations for 3 years and had 6monthly measurements of plasma potassium. A further 84 were recruited for study but 29 died within 6 months and 55 had to be withdrawn from the trial. The triamterene-containing preparation was discontinued most frequently (6/44) because of hypokalaemia (plasma potassium $<3.0 \mathrm{mmol} / \mathrm{l}$ ); amiloride (5/44) and spironolactone (1/47). The median fall in plasma potassium over 3 years in those patients not withdrawn because of hypokalaemia was similar in each case $(P>0.05)$ and possibly failed to reach significance because of the withdrawal rate $(9 \%)$. The trend was for a greater fall in those patients taking triamterene. The spironolactone-containing preparation may be the least unsatisfactory of the three.
\end{abstract}

\section{Introduction}

Thiazide-induced hypokalaemia is well known, ${ }^{1}$ but there is debate about its clinical importance. ${ }^{2,3}$ When attempting to prevent hypokalaemia a potassium supplement may prove adequate. ${ }^{4} \mathrm{~A}$ potassium-sparing drug may be preferable and has an additive diuretic effect, ${ }^{5,6}$ although none is totally satisfactory. ${ }^{7-9}$ Thiazide potassium-sparing diuretic combinations are amongst the most widely prescribed drugs especially in the elderly. ${ }^{10}$ The three most commonly prescribed preparations are: spironolactone $50 \mathrm{mg}+$ hydroflumethiazide $50 \mathrm{mg}$ (S/HFT-Aldactide 50); triamterene $50 \mathrm{mg}$ +hydrochlorothiazide $25 \mathrm{mg}$ (T/HCT-Dyazide) and amiloride $5 \mathrm{mg}$ +hydrochlorothiazide $50 \mathrm{mg}$ (A/HCTModuretic).

The use of potassium-sparing diuretics combined with thiazides has been studied in hypertensive patients in the short term ${ }^{1-15}$ and by one group in the long term. ${ }^{16}$ Chronic effects in patients with heart failure have received little attention and these three combinations have not previously been compared directly with each other. We have compared the long term effects of the above preparations on a group of elderly patients from both a clinical perspective and with reference to the effects on plasma potassium concentrations.

Correspondence: R. Gabriel, F.R.C.P.

*Present address: The London Hospital, London E1 1BB, UK.

Accepted: 22 December 1987

\section{Patients and methods}

Patients with cor pulmonale or ischaemic left ventricular failure, who received their first dose of a loop diuretic at the time of admission and required continued treatment, were considered for the study. Right or left ventricular failure was diagnosed using standard criteria. ${ }^{17,18}$ No patient was taking digoxin; all patients with cor pulmonale were receiving beta, agonist therapy. The recruitment period was 17 months, beginning in mid 1981. The study finished in the spring of 1986.

Exclusion criteria were: age $<65$ years, previous diuretic therapy, steroid-dependent airways disease, diabetes mellitus or hypertension, hepatic or renal disease, serum creatinine $>130 \mu \mathrm{mol} / \mathrm{l}$, plasma potassium $<3.5 \mathrm{mmol} / 1$ and daily diuretic requirement in excess of bumetanide $1 \mathrm{mg}$ or frusemide $40 \mathrm{mg}$. Verbal consent to participate in the trial was obtained. The design had been approved by the District Ethical Committee.

On discharge from hospital the loop diuretic was changed to one of the three study combinations. Patients were randomly allocated to receive one tablet of S/HFT, two tablets of T/HCT or one tablet of A/HCT and were followed-up for 3 years. Beta-agonist therapy was continued in all patients with cor pulmonale. Potassium supplementation and dietary advice were not given. The patients' general practitioners were informed of the study and asked not to alter therapy unless in an emergency.

(C) The Fellowship of Postgraduate Medicine, 1988 
Patients were seen in a general medical clinic by one of the authors (RG) within 4 weeks of discharge and remained under his care for the duration of the study. They were weighed under standard conditions, examined to ensure that heart failure was controlled and compliance with treatment assessed by direct questioning and tablet counts. Patients were seen frequently for repeat prescriptions and at $6,12,18,24$ and 36 months urine was tested for glucose and blood sampled. Plasma potassium concentrations were measured in the routine chemical pathology laboratory. The coefficient of variation of the assay was $1.1 \%$ at a concentration of $4.0 \mathrm{mmol} / \mathrm{l}$.

Criteria for withdrawal were: failure to comply with treatment, hypokalaemia (plasma potassium $<3.0 \mathrm{mmol} / \mathrm{l}$ ), development of diabetes mellitus (glycosuria and random glucose $>11.0 \mathrm{mmol} / \mathrm{l}$ ), side effects of the trial drugs or worsening heart failure.

The $\chi^{2}$ statistic and Wilcoxon's paired and unpaired tests were applied as appropriate. The data were not normally distributed and hence medians and interquartile ranges are quoted. The interquartile range includes $50 \%$ of values recorded with $25 \%$ lying above the upper figure and $25 \%$ below the lower. ${ }^{19}$ We compared results of analysis of combined data with findings from patients with left ventricular failure and cor pulmonale individually because beta-agonists may reduce plasma potassium concentrations. ${ }^{20}$

\section{Results}

One hundred and sixty-four patients began the study. Twenty-nine died before the first 6 month appointment and they are not considered further.
Biochemical data were therefore available for analysis from 135 patients (Table I). Between 6 and 36 months after starting treatment 22 patients died, $19 \%, 18 \%$ and $11 \%$ of those taking S/HFT, T/ HCT and A/HCT respectively (Table II). Eight patients were lost to follow-up. These losses from the groups were not significantly different from one another. Twenty-five of the 135 patients $(18 \%)$ were withdrawn from the study during this time. Hypokalaemia $(<3.0 \mathrm{mmol} / \mathrm{l})$ was responsible for 12 of these withdrawals: 6 taking T/HCT, 5 taking A/HCT and one taking S/HFT. The rate of withdrawal of patients taking the spironolactone-containing preparation just failed to reach significance compared with either of the other two combinations $(0.1>P>0.05)$. Half of the withdrawals due to hypokalaemia whilst taking T/HCT occurred in the first year $(3 / 6)$ whereas there were no hypokalaemic withdrawals before 18 months in those patients taking $\mathrm{A} / \mathrm{HCT}$ or S/HFT. Although median plasma potassium concentration fell similarly irrespective of beta-agonist treatment, hypokalaemic withdrawals were more common among those taking beta-agonists (5/37 compared with $7 / 98 ; \chi^{2}=1.23, P>0.25$ ).

Further analysis was confined to the 80 patients having completed 3 years of the trial. There was no significant difference in median weight at allocation and at the end of the study. Initial median plasma potassium concentration and interquartile range was $4.1(3.8-4.3) \mathrm{mmol} / \mathrm{l}$ and the final $3.5(3.2-$ 3.7) $\mathrm{mmol} / \mathrm{l}$. The fall in plasma potassium over time is shown in Table III.

At 36 months half the patients taking S/HFT and A/HCT had plasma potassium concentrations of $3.5 \mathrm{mmol} / 1$ or less but $75 \%$ of those taking T/HCT were below this value (Table III). Conversely,

Table I Demographic details of the 135 patients who survived more than 6 months after entering the trial

\begin{tabular}{|c|c|c|c|c|}
\hline & & \multicolumn{3}{|c|}{ Combination* } \\
\hline & & $S / H F T$ & $T / H C T$ & $A / H C T$ \\
\hline Total patient number & & 47 & 44 & 44 \\
\hline Sex Male & & 24 & 24 & 25 \\
\hline Female & & 23 & 20 & 19 \\
\hline Left ventricular failure & & 31 & 22 & 23 \\
\hline Cor pulmonale & & 16 & 22 & 21 \\
\hline Age (years) & - & $\begin{array}{c}72 \\
(65-82)\end{array}$ & $\begin{array}{c}72 \\
(66-84)\end{array}$ & $\begin{array}{c}73 \\
(64-86)\end{array}$ \\
\hline Plasma potassium $(\mathrm{mmol} / \mathrm{l})$ & & $\begin{array}{c}4.0 \\
(3.5-4.9)\end{array}$ & $\begin{array}{c}4.0 \\
(3.5-5.1)\end{array}$ & $\begin{array}{c}4.0 \\
(3.5-5.0)\end{array}$ \\
\hline Serum creatinine $(\mu \mathrm{mol} / \mathrm{l})$ & & $\begin{array}{c}109 \\
(62-128)\end{array}$ & $\begin{array}{c}109 \\
(67-128)\end{array}$ & $\begin{array}{c}111 \\
(58-128)\end{array}$ \\
\hline
\end{tabular}

*See text for abbreviations. Median values on entry to the study are shown for all variables with range in brackets. The potassium is the mean of results on admission and just prior to discharge. There was no significant difference between plasma potassium concentrations in men and women. 
Table II Outcome of the 135 patients who survived 6 months or more of the study.

\begin{tabular}{|c|c|c|c|c|}
\hline & \multicolumn{4}{|c|}{ Combination* } \\
\hline & $S / H F T$ & $T / H C T$ & $A / H C T$ & Totals \\
\hline Hypokalaemia $<3.5 \mathrm{mmol} / \mathrm{l}$ at any time in trial & 11 & 12 & 19 & 42 \\
\hline \multicolumn{5}{|l|}{ Withdrawals: } \\
\hline Hypokalaemia & 1 & 6 & 5 & 12 \\
\hline Diabetes & - & 1 & 1 & 2 \\
\hline Side effects & $2 \dagger$ & - & $1 \ddagger$ & 3 \\
\hline Worsening heart failure & 2 & 4 & 2 & 8 \\
\hline Total withdrawals & 5 & 11 & 9 & 25 \\
\hline \multicolumn{5}{|l|}{ Cause of death } \\
\hline Ischaemic heart disease & 2 & 1 & 2 & 5 \\
\hline Cor pulmonale & 2 & 4 & - & 6 \\
\hline Other & 5 & 3 & 3 & 11 \\
\hline Total deaths & 9 & 8 & 5 & 22 \\
\hline Lost to follow-up & 4 & 2 & 2 & 8 \\
\hline Completed 3 years & 29 & 23 & 28 & 80 \\
\hline Total patients & 47 & 44 & 44 & 135 \\
\hline
\end{tabular}

*See text for abbreviations. Side effects: tgynaecomastia; łhyperkalaemia and hyponatremia.

Table III Median plasma potassium concentrations in $\mathrm{mmol} / \mathrm{l}$ with interquartile ranges for the 80 patients completing the trial

\begin{tabular}{|c|c|c|c|c|c|c|}
\hline \multirow[b]{2}{*}{ Combination* and number of subjects $^{*}$} & \multicolumn{6}{|c|}{ Months } \\
\hline & 0 & 6 & 12 & 18 & 24 & 36 \\
\hline $\begin{array}{l}\text { S/HFT } \\
29\end{array}$ & $\begin{array}{c}4.0 \\
(3.9-4.2)\end{array}$ & $\begin{array}{c}4.1 \\
(3.9-4.3)\end{array}$ & $\begin{array}{c}3.9 \\
(3.8-4.2)\end{array}$ & $\begin{array}{c}3.8 \\
(3.6-4.0)\end{array}$ & $\begin{array}{c}3.6 \\
(3.5-3.9)\end{array}$ & $\begin{array}{c}3.5 \\
(3.3-3.7)\end{array}$ \\
\hline $\begin{array}{l}\mathrm{T} / \mathrm{HCT} \\
23\end{array}$ & $\begin{array}{c}4.2 \\
(3.7-4.5)\end{array}$ & $\begin{array}{l}4.1 \\
(3.9-4.4)\end{array}$ & $\begin{array}{c}3.9 \\
(3.7-4.1)\end{array}$ & $\begin{array}{c}3.8 \\
(3.5-4.0)\end{array}$ & $\begin{array}{c}3.6 \\
(3.5-3.8)\end{array}$ & $\begin{array}{c}3.3 \\
(3.1-3.5)\end{array}$ \\
\hline $\begin{array}{l}\text { A/HCT } \\
28\end{array}$ & $\begin{array}{c}4.0 \\
(3.9-4.2)\end{array}$ & $\begin{array}{c}4.0 \\
(3.7-4.1)\end{array}$ & $\begin{array}{c}3.9 \\
(3.6-4.0)\end{array}$ & $\begin{array}{c}3.7 \\
(3.5-4.0)\end{array}$ & $\begin{array}{c}3.6 \\
(3.3-3.9)\end{array}$ & $\begin{array}{c}3.5 \\
(3.1-3.7)\end{array}$ \\
\hline
\end{tabular}

*See text for abbreviations.

plasma potassium was $4.0 \mathrm{mmol} / 1$ or more in 3 patients treated with S/HFT and in 4 each of those who took T/HCT or A/HCT. There was no significant difference at any time in plasma potassium concentration between those patients taking betaagonist therapy and those who were not.

\section{Discussion}

We have shown that median plasma potassium concentrations fell progressively in our 80 patients over 36 months of treatment. We found that $S /$ HFT caused least hypokalaemia, T/HCT the most and A/HCT an intermediate amount. The failure of the differences to reach statistical significance is probably due to withdrawal of patients because of severe hypokalaemia.

Because the patients were seen frequently, had their tablets counted and were questioned regarding therapy, it is improbable that any additional diuretic or potassium supplement was prescribed by a general practitioner.

The thiazide dose was equipotent because we used two tablets of T/HCT and only one of each of the other preparations. ${ }^{21}$ The quantities of potassium-retaining drugs in the combinations studied may not be precisely equivalent. 14,15,22 Nevertheless our principal aim was to determine the long term effects of the three most commonly prescribed thiazide potassium-sparing diuretic combinations in patients with oedema. The median fall in plasma potassium concentration in our 80 patients $(0.5 \mathrm{mmol} / 1$ over 3 years $)$ was very similar to that found in patients in the Medical Research Council Trial who took bendrofluazide $10 \mathrm{mg}$ daily. ${ }^{23}$ This suggests little benefit from the potassium-sparing component of the combinations which is contrary to the advice given in Prescribers' Journal in $1985 .{ }^{24}$ Our figure of $0.5 \mathrm{mmol} / 1$ may be 
an underestimate because of the withdrawal of 12 patients whose plasma potassium fell below $3.5 \mathrm{mmol} / 1$.

Moderate hypokalaemia $(<3.5 \mathrm{mmol} / \mathrm{l})$ developed in 42 out of 135 elderly patients receiving the study drugs for more than 6 months for heart failure. Severe hypokalaemia $(<3.0 \mathrm{mmol} / \mathrm{l})$ developed at up to 36 months after starting treatment. This conflicts with the observations of Morgan and Davidson, ${ }^{1}$ who cited short term studies except for one which lasted 2 years, but is supported by other published work. ${ }^{2}$ Dietary potassium intake in this elderly population living in a deprived inner city area may have been inadequate.

We recommend that plasma potassium should be assayed within 6 months of starting elderly patients on therapy with any of these combinations and then regularly for the duration of treatment.

\section{References}

1. Morgan, D.B. \& Davidson, C. Hypokalaemia and diuretics: An analysis of publications. Br Med J 1980, 1: 905-908.

2. Potassium-sparing diuretics - when are they really needed? Drug Ther Bull 1985, 23: 17-20.

3. Freis, E.D. The cardiovascular risks of thiazide diuretics. Clin Pharmacol Ther 1986, 39: 239-244.

4. Hussain, M., Walton, K., Davidson, C. \& Morgan, D.B. A study of two diuretic/potassium combinations in heart failure. Postgrad Med J 1985, 61: 29-33.

5. Ogden, D.A., Scherr, L., Spritz, N. \& Rubin, A.L. A comparison of the properties of chlorothiazide, spironolactone and a combination of both as diuretic agents. N Engl J Med 1961, 265: 358-362.

6. Maclean, D. \& Tudhope, G.R. Modern diuretic treatment. Br Med J 1983, 286: 1419-1422.

7. Reynolds, J.E.F. (ed) Martindale. The Extra Pharmacopoeia. Pharmaceutical Press, London, 1982.

8. Editorial. Triamterene and the kidney. Lancet 1986, i: 424.

9. Jaffey, L. \& Martin, A. Malignant hyperkalaemia after amiloride/hydrochlorothiazide treatment. Lancet 1981, i: 1272.

10. Levy, D.W. \& Lye, M. Diuretics and potassium in the elderly. J R Coll Physicians Lond 1987, 21: 148-152.

11. George, C.F., Breckenridge, A.M. \& Dollery, C.T. Comparison of the potassium retaining effects of amiloride and spironolactone in hypertensive patients with thiazide induced hypokalaemia. Lancet 1973, ii: 1288-1290.

12. Cocke, T.B., Solomon, F. \& Gilmore, H.R. Double blind comparison of triamterine plus hydrochlorothiazide and spironolactone plus hydrochloro-thiazide in the treatment of hypertension. J Clin Pharmacol 1977, 17: 334-338.

13. Berglund, G. \& Anderson, M.D. Hydrochlothiazide and spironolactone alone and in a fixed combination in hypertension. Curr Ther Res 1980, 27: 360-364.

14. Ramsay, L.E., Hettiarachi, J., Fraser, R. \& Morton, J.J. Amiloride, spironolactone and potassium chloride in thiazide treated hypertensive patients. Clin Pharmacol Ther 1980, 27: 533-543.
The spironolactone-containing preparation appears least likely to induce hypokalaemia. Twelve patients had to be withdrawn because of hypokalaemia and because no preparation caused significantly more withdrawals than any other, a Type-II error $^{25}$ may have accounted for our inability to show statistically significant differences between them. If it had been acceptable to continue treatment in all patients for 3 years it is probable that we would have shown significantly less hypokalaemia with the spironolactone-containing preparation than with the others.

\section{Acknowledgements}

We thank Mrs Jane Wadsworth, Statistician, and staff of the Computer Unit and of the Department of Diagnostic Chemical Pathology for their helpful advice.

15. Jackson, P.R., Ramsay, L.E. \& Wakefield, V. Relative potency of spironolactone, triamterine and potassium chloride in thiazide induced hypokalaemia. $\mathrm{Br} \mathrm{J}$ Clin Pharmacol 1982, 14: 257-263.

16. Amery, A., Brixko, P., Clement, D. et al. European Working Party on High Blood Pressure In The Elderly. Mortality and morbidity from the European Working Party on High Blood Pressure In The Elderly trial. Lancet 1985 , i: $1349-1354$.

17. Gibson, D.G. Heart failure: Ventricular disease. In:co Weatherall, D.J., Ledingham, J.G.G. \& Warrell, D.A. (eds) Oxford Textbook of Medicine. Oxford University Press, Oxford, 1987, pp. 13.84-98.

18. Pritchard, J.S. Cor pulmonale. In: Weatherall, D.J., Ledingham, J.G.G. \& Warrell, D.A. (eds) Oxford Textbook of Medicine. Oxford University Press, Oxford, 1987; pp. 13.350-355.

19. Armitage, P. \& Berry, G. Statistical Methods In Medical Research. Blackwell Scientific Publications, Oxford, 1987, p. 34.

20. Epstein, F.M. \& Rosa, R.M. Adrenergic control of serum potassium. $N$ Engl $J$ Med 1983, 309: 1450-1451.

21. Joint Formulary Committee. British National Formulary. British Medical Association \& The Pharmaceutical Society of Great Britain, 1986, ii: 70.

22. Bull, M.B. \& Laragh, J.H. Amiloride, a potassium sparing natriuretic agent. Circulation 1968, 37: 45-53.

23. Medical Research Council Working Party on Mild to Moderate Hypertension. Adverse reactions to bendrofluazide and propranol for the treatment of mild hypertension. Lancet 1981, ii: 540-543.

24. Williams, B.O. Use and misuse of diuretics in the elderly. Prescribers' Journal 1985, 25: 51-56.

25. Armitage, P. \& Berry, G. Statistical Methods In Medical Research. Blackwell Scientific Publications, Oxford, 1987, p. 181. 